\title{
On emission permit auction vs. allocation and the structural adjustment of incumbent power generators in Australia
}

\author{
Paul Simshauser* \\ Babcock \& Brown \\ Level 23, The Chifley Tower \\ 2 Chifley Square, Sydney, NSW, 2000.
}

\begin{abstract}
This article reviews the case for structural adjustment assistance to power generators following the implementation of an Australian Emissions Trading Scheme (ETS). Due to the predominance of $\mathrm{CO}_{2}$ intensive coal-fired generating capacity in Australia, profound structural changes to the supply-side are expected. This article finds that a once-off partial allocation of permits would not impair the economic efficiency of the ETS, would not have the effect of re-directing existing government expenditures, would minimize transaction costs and most importantly, would help to ensure power system stability throughout this major microeconomic reform.
\end{abstract}

\section{Introduction}

Australia's energy-intensive economy is about to embark upon a very significant microeconomic reform; implementing an Emissions Trading Scheme (ETS). To put the impact of an ETS on Australia's carbon-intensive economy into some context, a A \$25/t carbon cost would represent $1 \%$ of national GDP compared to just $0.28 \%$ in the case of the EU. ${ }^{1}$ But despite this, the ETS policy is widely supported amongst emissions intensive industries, including power generators, which currently represent about $35 \%$ of national emissions.

It is widely accepted that the introduction of an ETS will result in profound structural changes in power generation in Australia (Ergas, 2008). The power industry placed its support behind the policy with the presumption that some form of economic adjustment assistance would form an integral part of the reforms, most likely through a once-off allocation of permits to the sector. The economic basis for this commonly held view appears logical enough - following the precedence set by the EU ETS, the State Governments" "National Emissions Trading Taskforce" (NETT, 2007) suggested that a portion of emission permits be allocated to generators amongst other industries likely to be adversely effected with the balance to be auctioned. Similarly, the former Howard Federal Government's “Prime Ministers Task Group on Emissions Trading” (TGET, 2007) arrived at a similar conclusion, advocating a once-and-for-all initial allocation of permits to industries disproportionately affected. But with the change of Federal Government in late-2007, an independent greenhouse review was subsequently commissioned, the 'Garnaut Review', with a view to advising on ETS policy. To the surprise of the power industry, the Garnaut Review's recommendation was an 'all-auction' approach to emission permits and while adjustment mechanisms should go hand in hand with an ETS, power generators should be excluded from such mechanisms.

The purpose of this article is to review the relative merits of structural adjustment assistance in the special case of power generators under an ETS. This article is structured as follows; Section 2 provides an overview of the Garnaut Review on ETS in relation to power generators. Section 3 estimates the required investment in new generating capacity for the National Electricity Market (NEM). Section 4 then considers the survival of the firm under an ETS while Section 5 considers

\footnotetext{
* Paul Simshauser is also Adjunct Professor at the Griffith Business School. The author would like to acknowledge Ross Rolfe, Craig Nalder and Thao Doan for their helpful comments. However the views expressed in this paper are those of the author and not necessarily those of Babcock \& Brown.

${ }^{1}$ Based on Australian GDP of c.\$1.1 billion and 432Mt of $\mathrm{CO}_{2}$, and EU GDP of $€ 11$ billion and $2000 \mathrm{Mt}^{\circ} \mathrm{CO}_{2}$.
} 
the short, medium and long run impacts of an all auction approach to permits. Section 6 provides six potential policy responses to support structural adjustment and Section 7 concludes.

\section{The Garnaut Review}

Garnaut (2008) recommended an all-auction approach to permit allocation with respect to power generators. While perhaps unexpected such an approach is not without economic justification. There are many economic arguments which, in theory at least, support an all-auction approach. However, as is often the case, application and the harsh realities of the real world cause good theory to break down once scenario-framing assumptions are lifted. Compounding the situation was the manner in which the Garnaut Review opted to commence its inquiry; a media campaign which labeled power generators as "rent-seekers who have an objective of corrupting the scheme". The concepts of "rent seeking" and "scheme corruption" are used extensively in economic literature and refer to firms who stand to lose monopoly rents in a pre-reformed market, and in the event are seeking to block painful microeconomic reform and economic progress in order to retain the monopoly rents (see for example Johnson and Salop, 1980; Srinivasan, 1985; Johnson, 1994). But in the case at hand, generators do not extract monopoly rents, and no generator in Australia opposes the implementation of an ETS. In fact in both cases, it is quite the opposite since the market is highly competitive and the industry has gone 'on record' as supporting an ETS. On generators, Garnaut (2008, p.33) noted that:

Free allocation would be highly complex, generate high transaction costs, and require value-based judgements. If permits are to be freely allocated in part, or wholly, to existing emitters, a methodology must be developed for doing so... The definition of principles, collection and application of data, and resolution of disputes would be timeconsuming, and could have a material effect on the time required for introduction of an ETS. It would seem impractical for Australia to administer a free allocation scheme prior to introduction of the ETS in 2010. The complexity of the process, and the large amounts of money at stake, encourage pressure on government decision making processes, and the dissipation of economic value in rent-seeking behaviour...

Yet an allocation process for generators would seem quite a straight forward process since a vast body of independent quantitative work already exists through the State Government NETT (2007) Report and most power market economic advisory firms ${ }^{2}$ have undertaken extensive modelling with similar results being produced. On transaction costs, Dixit and Olsen (2000) noted that different economists define these differently, but all agree that the resources devoted to transactions have alternate uses and, thus, an opportunity cost. A once-off initial allocation would likely lead to lesser costs than an all-auction approach given the vast level of analysis that would be required by all generating firms. Indeed, ACIL Tasman (2007) noted that an allocation policy might fail the test of efficiency relative to an all-auction approach 'but for' the unusual characteristics of the power generation sector, viz. transaction costs would be especially small because large losses are involved, the losses are very easily identified, the number of effected parties is small, and the quantification of the requirement for structural adjustment assistance is readily available using existing Government modelling such as NETT (2007). And while disputes may arise and lead to an extended process, with about $\$ 54$ billion of existing power station debt and equity capital at stake (see Table 1), this would hardly seem a satisfactory reason to ignore an industry that will face a very disproportionate impact relative to the balance of economic agents.

\footnotetext{
${ }^{2}$ For example see MMA (2006), CRA in NGF (2007), Frontier Economics (2008), ACIL Tasman (2008).
} 
Table 1: $\quad$ Value of Australia's power stations as at 30 June 2007

\begin{tabular}{|c|c|c|c|c|c|c|c|c|c|}
\hline $\begin{array}{l}\text { Generation } \\
\text { Technology }\end{array}$ & $\begin{array}{c}\text { Installed } \\
\text { Capacity* } \\
\text { (MW) }\end{array}$ & $\begin{array}{c}\text { Energy } \\
\text { Produced } \\
\text { (GWh) }\end{array}$ & $\begin{array}{c}\mathrm{CO}_{2} \\
\text { Footprint } \\
\text { (t/MWh) }\end{array}$ & $\begin{array}{c}\text { Replacement } \\
\text { Cost\# } \\
(\$ / \mathrm{kW})\end{array}$ & $\begin{array}{c}\text { Replacement } \\
\text { Value } \\
(\$ \mathrm{~m})\end{array}$ & $\begin{array}{c}\text { Average } \\
\text { Fleet Age* } \\
\text { (Yrs) }\end{array}$ & $\begin{array}{c}\text { Total Useful } \\
\text { Life\# } \\
\text { (Yrs) }\end{array}$ & $\begin{array}{c}\text { Remaining } \\
\text { Useful Life } \\
\text { (Yrs) }\end{array}$ & $\begin{array}{c}\text { Depreciated } \\
\text { Value } \\
(\$ \mathrm{~m})\end{array}$ \\
\hline Hydro & 7,609 & 13,726 & 0.00 & 2,500 & 19,023 & 37.2 & 100 & 62.8 & 11,953 \\
\hline Black Coal & 22,601 & 128,386 & 0.90 & 2,250 & 50,852 & 23.5 & 50 & 26.5 & 26,957 \\
\hline Brown Coal & 7,335 & 55,506 & 1.35 & 2,750 & 20,171 & 28.1 & 50 & 21.9 & 8,842 \\
\hline Natural Gas & 6,688 & 15,282 & 0.60 & 1,100 & 7,357 & 15.2 & 30 & 14.8 & 3,629 \\
\hline NGCC & 2,154 & 12,400 & 0.40 & 1,550 & 3,339 & 5.0 & 30 & 25.0 & 2,782 \\
\hline TOTAL & 46,387 & 225,300 & $1.00 \mathrm{avg}$ & 2,172 & 100,742 & 24.4 & 54 & 30.0 & 54,164 \\
\hline
\end{tabular}

\subsection{On the potential for pass-through and economic losses}

At the heart of Garnaut (2008) is an assumption that power generators will be able to pass on the cost of emission permits acquired under an all-auction approach. Yet Garnaut (2008) observed that emissions trading costs in the EU were taken into account in $70 \%$ of 'marginal' pricing decisions in power generation. Even if $70 \%$ of output was priced on a pass-through basis, then there is an explicit acceptance that $30 \%$ of losses are predictable. Sijm et al. (2005, pp55-61) undertook extensive statistical analysis of the pass-through rate of $\mathrm{CO}_{2}$ prices in Germany and Netherlands electricity systems. Their analysis found a base load pass-through rate of $58 \%$ in Germany and only $48 \%$ in the Netherlands. Analysis using extensive system-wide dynamic partial equilibrium modelling results by economics advisory MMA in NETTS (2006), CRA in NGF (2008), Frontier Economics (2008), and in Simshauser and Doan (2009) forecast substantial income losses for coal generators, being in the order of $20-30 \%$ for black coal and $70-80 \%$ for brown coal.

\subsection{The impact on electricity prices}

Garnaut (2008) noted that an argument had been put forward that free permits should be allocated to coal generators in order to limit the effects of an ETS on electricity prices - but that such a claim is fallacious. This is indeed correct, yet the author is unaware of any literature or any argument by power generators (in the Australian case) that an allocation of permits might somehow keep electricity prices from rising. There is absolutely no doubt that electricity prices will rise, and rise very substantially. The relevant question, however, is the extent of price rises. Under an all-auction approach, incentives for participants change radically. This was the theme in Simshauser and Doan (2009) where results of dynamic partial equilibrium modelling showed "excessive" price increases driven by the economic withholding of capacity as a rational and predictable response to stranded assets created by an all-auction approach to emission permits. There is empirical evidence which supports such a theory as noted by Ergas (2008, p.2):

There are some circumstances where auctioning might [adversely] change the behaviour of emitters in their respective output markets relative to [allocation]. These effects are complex and depend on the specific industry context. However, given the economic importance of key emitting industries such as the electricity supply industry, they cannot be dismissed lightly... [Studies have found] a clear positive relationship between entry fees and consumer prices when licences are allocated via an auction process as opposed to being [allocated]. In the short term, where licences had been auctioned, players charged significantly higher prices than if they had been [allocated]...

\section{Australia's forward power plant requirements}

The power sector in Australia has gone through some particularly acute microeconomic reforms over the past 20 years including industry restructuring, deregulation and the formation of the NEM. Throughout these reforms, the key "shock-absorber" from a policy and structural adjustment perspective was the fact that the power industry was vastly oversupplied with highly reliable and monopoly-built low cost generating plant capacity. Consequently, despite the radical and painful nature of the reforms, the potential for security of supply violations (i.e. blackouts) or 
adverse product market effects (i.e. sustained high prices) under conditions of power system duress were virtually non-existent. Not surprisingly, the Australian East Coast is credited with implementing one of the most successful power industry reforms in the world.

But from a policy perspective, 2008 is a very different environment and 2010 is likely to be even more so. The NEM is now stretched from a supply-side perspective in all regions. In 2007/08 the NEM-wide system reserve was just $10 \%$ compared to the world benchmark of $15 \%$. Based on median load forecasts, NEMMCo (2007) predicts that planning reserves will fall to just $8 \%$ by the start of the ETS in 2010. Thus all existing plant will need to remain operational (and financially viable) and vast amounts of new investment will be required simply to keep the lights on. To put this into perspective, throughout of the NEM's history, reserve plant margins have been between $20 \%$ and $40 \%$ across the various regions (Simshauser, 2005). At no time has the entire system-wide reserve been at or below $10 \%$ during a major reform.

The combined requirement for new plant over the course of the next 10 -years is about $8,500 \mathrm{MW}$ which by Australian standards is very material (NEMMCo, 2007; IMOWA, 2007). Taking template costs for combined cycle base load gas-fired plant at $\mathrm{A} \$ 1550 / \mathrm{kW}$ and open cycle gas turbine peaking plant at $\mathrm{A} \$ 1100 / \mathrm{kW}$ this represents an investment task of $\mathrm{A} \$ 12$ billion (22\% of the NEM's current asset stock) over 10 years. Perhaps more significantly, if Australia is to meet its likely emission trajectory targets, then many existing power stations must, by definition, be closed down. If it is assumed that just $15 \%$ of existing coal-fired power generating capacity is replaced over the next 10 years with base load gas plant, then the investment task rises from $A \$ 12$ billion to A $\$ 20$ billion. And the investment task becomes even more complicated by leaddevelopment times now appearing in the market for power generating equipment. When development delays, equipment lead-order times and construction lags are aggregated, it is not unreasonable to assume that a NGCC plant would now take between 5-6 years from start to completion (up from 31/2 years), and an OCGT plant between 3-4 years (up from 21/2 years).

Most fundamentally, a particularly important characteristic of power generation development in Australia is the highly specialised nature of this field of economic activity. Between 1996 and 2007, only 14 firms $^{3}$ successfully planned, financed and added large-scale power station capacity to the Australian grid. Just 10 of these firms remain active in the development space at the time of writing. Since the NEM power system is very finely balanced vis-à-vis supply and demand, countering exit before entry should be considered an important policy objective. This then turns to the more relevant question and impacts of survival of the firm vs. survival of the plant.

\section{Survival of the firm vs. survival of the plant}

In order to assess whether there is a sound theoretical argument for any form of structural adjustment for power generators, we must turn to the literature on microeconomic reform to make a reasoned assessment.

\subsection{On the theoretical basis for structural adjustment}

Economists typically commence analysis of reforms with the notion that there is no basis for transitional assistance or compensation mechanisms whatsoever to offset direct or indirect losses associated with a policy that is designed to drive economic efficiency. Were it not for this default approach, governments would not be able to function properly as Pasour (1973), Neary (1982), Johnson (1994), Argy (1999) and many others have noted. The sheer complexity of measuring economy-wide losses for every policy change is simply not feasible as transaction costs (i.e. the measurement and the delivery of assistance) would vastly exceed the likely benefits. In addition, the delivery of assistance would impair the economic efficiency that a policy measure is trying to

\footnotetext{
${ }^{3}$ AGL, Babcock \& Brown, Origin Energy, Transfield, Delta Electricity, Griffin Energy, International Power, ERM Power, Snowy Hydro, TRUenergy, Tarong Energy, CS Energy, QGC and Verve Energy. Source: esaa (2008). 
drive in the first place. In the event, potential policy winners (e.g. consumers encouraging reform) would be 'taxed' in order to 'reimburse' the policy losers (i.e. firms resisting reform). But perhaps most significantly, if it was the case that the "default position" for every policy change was likely to lead to an adjustment program, then the outcome would more than likely lead to what economists refer to as "moral hazard" - where investors believe that their future actions are protected against any form of policy change through government adjustment.

Argy (1999) and Garnaut (2008) have noted that there are certain conditions where structural adjustment assistance is desirable or necessary on economic efficiency grounds. The condition as to when this binds invariably comes down to whether a reform is likely to lead to a material misallocation of resources. In Argy (1999), an industry is suggested to qualify for structural adjustment if reform shocks are large, policy driven events, breach long standing expectations, and are likely to produce uneven net benefits or disproportionate losses. In order to test the application of the abovementioned, it is necessary to consolidate the key concepts from the economic theory of structural adjustment and how this might apply in practice to power generators in Australia given an ETS reform.

\subsection{Survival of the firm}

If it is accepted that coal plant will be adversely impacted by an ETS, then it follows that a large number of these generators will reach a point of temporary or permanent financial distress earlier than a business-as-usual scenario would indicate. At the very heart of the ETS permit allocation debate for power generators in Australia is the survival and recovery of the affected power generating firms under an all-auction approach. This might manifest itself in one of two ways; (1) outright organisational bankruptcy and subsequent industry 'exit', or (2) temporary financial distress in which case the firm will be entirely preoccupied with remedial measures, 'distraction' - and in the event will not in a position to invest in forward capacity over a sustained period of time spanning several years arising from its distressed financial state. For our purposes, the combination of 'exit' and 'distraction' might be considered as 'survival of the pack' since in the short and intermediate run they are likely to have an identical effect on the dynamic efficiency of the power sector.

The primary issue here is not the survival of specific power plants. Inevitably, whether emission permits are auctioned or allocated, there is no reason to believe that the useful economic life of a high-emitting power station should be materially different (provided permits are fungible). That is, if permits are fungible and can be transferred to new plant, and the existence of allocated permits is not contingent upon the plant remaining in service, then allocated permits will not form a production subsidy under a Cap and Trade market model. Henney and Nuehoff (2008) noted that in the EU, allocated permits were not fungible to the firm such that if the plant was closed, allocated emission permits would be forfeited. This, they argue, initiates a perverse incentive for inefficient plant to remain in service. Clearly, such an outcome would be entirely suboptimal from an emission policy perspective.

\subsection{Entry before exit and the speed of adjustment}

NEM power system reserves will be tight at best and entirely inadequate at worst when an ETS commences in Australia in 2010. Moreover, the existing coal plant stock is aging as Table 1 noted. In the absence of significant ongoing maintenance expenditure, which can only be justified on the basis of an ongoing economic life, the reliability of existing plant will predictably deteriorate placing additional pressure on power system reserves. This is important. A 15\% reserve planning margin is highly contingent upon existing plant maintaining high levels of reliability. If plant reliability deteriorates, then planning margins must necessarily rise above $15 \%$ to compensate. 
Since the power system requires substantial supply-side structural adjustment, transitioning from a predominately $\mathrm{CO}_{2}$ intensive coal-fired system (82\% per Table 1$)$ to a less $\mathrm{CO}_{2}$ intensive system, the more general issue of entry before exit would seem to be especially important. A recycling of capital to ensure structural adjustment occurs is required. Johnson (1994) noted that one of the difficulties arising from structural adjustment is the contraction of production and investment by firms adversely affected. Most notably, he argued that financial duress can be so acute as to lead to firms exiting before beneficiaries enter the market. Such a vacuum in an industry can lead to unemployment and underutilisation of fixed capital due to the immobility of plant - which is obviously a central problem in the case if power generating equipment given its exclusive asset specificity characteristic.

Nsouli et al. (2002) considered whether reform should be based on what they describe as "shock therapy", or whether a more gradual approach should be adopted. While not specifically considering the case of an ETS, shock therapy can be likened to an 'all-auction' permit policy, and the gradual approach to a 'once-and-for-all' allocation of permits. They noted that the identification of risks associated with each adjustment and reform strategy is critical, and importantly, that the higher the financing requirements of a reform, the higher the probability of 'reform failure'. Since an ETS reform necessarily places financial pressure on incumbent coal generators, it follows that a key risk must be security of supply.

Nsouli et al. (2002) noted that rapid adjustment requiring substantial structural reform with high financing requirements will more than likely lead to a material misallocation of resources - this being acknowledged earlier as the key trigger for providing structural adjustment. Since the cost of new capacity required in the NEM is thought to be up to A $\$ 20$ billion over the next 10 years, a significant $37 \%$ of the current asset base, it follows that the financing requirement of reform is extremely large by Australian standards and therefore reform has an especially high potential for failure and is thus capable of leading to a material misallocation of resources. In this regard, Johnson (1994, p.407) noted that:

“...[reform] managers must ensure that there is adequate legal, institutional and analytical framework within which program managers can deal, most notably, with issues related to exit before entry... One of the difficulties that adjustment program managers face is that of contraction of economic activities (production and investment) by firms that are hurt by the adjustment (exit) before firms which benefit from the adjustment begin to expand and replace the declining ones (entry). This problem of exit before entry can lead to increased unemployment, underutilisation of capacity, with consistent pressures from those persons adversely affected... A properly designed [reform] must include measures to speed up entry, minimise the unemployment and underutilisation of capacity without slowing down the desired structural adjustment... Such an analytical and policy framework is possible because the nature, if not the precise extent, of the exit-before-entry problem is usually predictable... Such 'adjustment costs' are not unpredictable and are well known in economic theory..."

\section{Short, intermediate and long run applied effects of an all-auction approach}

In order to deal with the special case of power generation in an applied sense, three time-horizons are examined, the short run (1-3 years) being roughly the timeframe in which the plant stock is largely fixed, the intermediate run (3-5 years) in which sunk plant capacity becomes 'contingently variable', and the long run, in which substantial new capacity can be added (6+ years). This specific analysis relates to an all-auction approach using the Victorian region of the NEM as illustrative. 


\subsection{Short run effects from an all-auction approach}

Argy (1999) noted that the presence of structural adjustment assistance tends to reduce the shortrun economic disruption of policy changes and thus its absence can enhance disruption. Under an all-auction approach, it would not be contentious to argue that most of the brown coal generators in Victoria will face a high risk of financial distress within 10 years since $\mathrm{CO}_{2}$ price pass-through rates are unlikely to be sustained at $100 \%$ of the current $\mathrm{NEM} \mathrm{CO}_{2}$ coefficient (1.0t per MWh) let alone $100 \%$ of the average Victorian $\mathrm{CO}_{2}$ coefficient (1.35t/MWh).

In NETT (2007), CRA (2008) and Simshauser and Doan (2009) Victorian enterprise losses were forecast to be in the order of $70-80 \%$. If this is indeed the case, why would any Victorian generator, under conditions of tight supply-demand, lock in forward electricity contracts at the present $A \$ 45-50$ which virtually ensures bankruptcy in any event? In this first horizon of 1-3 years, the short answer is that they will not, and one of two step-change adjustment outcomes is predictable given the fixed nature of the supply stock in the short run; (a) electricity prices will rise by at least two-fold to approximately $\$ 100 / \mathrm{MWh}$ ex $-\mathrm{CO}_{2}$ as modelled in Simshauser and Doan (2009) during the first horizon via the economic withholding of capacity from spot markets; or (b) generators will not even offer forward contracts, thus leaving electricity retailers exposed entirely to the asymmetric and highly volatile energy-only spot market. Given the political economy of electricity, either scenario would be unbearable but the latter scenario would represent a manifest and systemic failure of Australia's deregulated electricity market. To be sure, it is more than a theoretical possibility - forward trade activity in the NEM beyond 2010 remains worryingly thin.

\subsection{Intermediate run effects from an all-auction approach}

In the intermediate run, structural adjustment assistance can minimise the effects of long term unemployment (Argy, 1999). In the power industry under an all-auction approach, capital works and the effects of long term capacity retirement should be considered simultaneously, since the latter ultimately drives the extent of maintenance capital expenditure. That is, if sunk plant maintenance and capital works activities begin to cease, so too does the demand for power industry labour, specifically power engineers and technicians. In this second horizon, that being the period between 3-5 years, companies would demonstrably lack the forward financial capacity to reinvest and maintain assets to their current standards of preventive maintenance given, by this stage in the reform cycle, the prognosis for economic life must now be bordering on critical with the entry of new low emitting plant imminent.

In Garnaut (2008), it was implied that entry and exit would be perfectly matched, and the notion of declining performance of existing plant was assumed away. The author considers that intentional exit before entry is, in reality, unlikely given the political economy associated with electricity supply in a modern economy. But what is predictable is a material deterioration in power plant reliability resulting in unintentional blackouts; not because of engineering incompetence, and not because of market manipulation, but because of long-range financial incapacity to maintain plant at current reliability levels and time-lags associated with replacement capacity.

\subsection{Long run effects from an all auction approach}

Argy (1999) noted that in the long run where reforms are policy induced and represent a breach with long standing traditions or legitimate expectations reflecting a regulatory taking, there is a case for structural adjustment assistance because such intervention can substantially mitigate against perceptions of sovereign risk. As an ETS is an exclusively 'investment-led' reform, guarding against sovereign risk would seem to be especially important in the Australian case given that the majority of the capital invested in Australia's power stations comes directly from foreign firms, foreign institutional investors and foreign banks. In this third horizon under an allauction approach, the debt and equity capital markets will recall large capital losses incurred in 
the second horizon. (Note: the debt and equity capital markets at the time of writing continually refer back to large losses incurred by power generators in the NEM following market deregulation in the late-1990s). This will have the effect of increasing the cost of debt and equity capital in Australia's power sector. And since the power generation industry is one of the world's most capital intensive industries, a rising cost of capital ultimately manifests itself in adverse effects on consumer pricing.

Compounding all issues here is that in this third horizon, 'plant exit' becomes certain but the entry of MW-for-MW replacement capacity must be considered infinitely less certain and therefore a non-trivial issue. While a theoretical economic model of the power system will ensure that entry occurs before exit, what a model cannot anticipate is the impact of Corporations Law on the decisions of Directors who, if incorrect on their judgement of solvency, are held personally liable.

\section{Policy implications of an ETS}

An ETS is indeed a complex policy reform since it touches on a vast number of industries very adversely. And coal generators will be disproportionately impacted while providing what can only be described as an essential service. But the reforms being contemplated by the Australian Government are necessary, and this article should not be interpreted as anything other than a discussion on structural adjustment. The issue here is the requirement for simultaneous offsetting policies of structural adjustment to ensure overall scheme success. With consideration for the case of Australian black and brown coal generators whose expected losses are thought to be in the range of $20 \%$ to $80 \%$ of individual asset stocks respectively, there would appear to be six economic arguments which support a policy of structural adjustment:

1. Structural adjustment assistance to power generators is unlikely to impair the economic efficiency of an ETS reform because far from being a production subsidy, an allocation of permits, if fungible to the firm, is likely to enhance the predictability of environmentally inefficient power station exit.

2. Whereas most structural adjustment programs require the raising of funds from new sources, an ETS creates a funding source to finance structural adjustment in its own right. The existence of income and capital gains taxes will adjust the position of firms experiencing windfall gains (e.g. hydro and gas plant) which thus provides additional inherent funding routes for government.

3. Reforms are usually aimed at some form of wealth redistribution. Previous electricity reforms (restructuring and deregulation) were implemented to lower consumer prices by removing rigidities that protected the profits of inefficient monopoly producers. An ETS on the other hand simply aims to correct an environmental externality. Consequently, a Pareto policy objective of making no economic agent worse off would seem to be a relevant policy objective.

4. The notion of "moral hazard" is not relevant since the issue at hand is the treatment of sunk and previously committed generating plant via a once-and-for-all allocation of permits, not future plant.

5. On transaction costs, the complexity of measuring generator impacts is well documented and a relatively straight forward task given the impact is large and the number of effected entities is small. There is no evidence to suggest that a once-off allocation process is any less efficient than annual auctions from a partial equilibrium perspective.

6. In the absence of structural adjustment assistance, it seems clear that the survival of a number of members of the pack, those 10 firms that will be required to drive investment 
in new lower emitting generating capacity, becomes questionable in the intermediate run, which will have implications for the long run stability of the power grid and the performance of the ETS policy.

The case for policy intervention on economic efficiency grounds invariably comes down to whether or not reform is likely to lead to a material misallocation of resources and the view in this article is that under an all-auction approach, such an outcome is entirely predictable and inevitable via excessive electricity price increases based on survival in the short run, unintentional black-outs through deteriorating plant reliability levels in the intermediate run, and rising risk premiums on debt and equity capital in the long run. And somewhat alarmingly, policy intervention by government to short-circuit the price increases in the short run will only serve to exacerbate the forecast effects in the intermediate and long run. Consequently, these short, intermediate and long run effects are in every sense, non-trivial.

In terms of structural adjustment, it would seem logical that adversely effected members of the pack need to focus on matters other than distressed balance sheets. When an ETS is implemented, its very success in power industry environmental reform relies on the investment performance of the pack since the policy itself is, as noted earlier, 'investment led'. So how then is structural adjustment best dealt with in the case of Australian power generators?

In the view of the author, the most optimal solution is to provide a once-and-for-all fungible 'permit allocation stream' since it effectively marks-to-market the potential liability of an ETS. Whether emission prices start out high or low, allocated permit values automatically adjust to reflect such conditions. An allocation does not require the raising of funds or the re-direction of existing government expenditure. Nor does it corrupt the scheme because if permits are fungible, then (a) allocations do not represent a production subsidy and will not impact on the static productive efficiency of an ETS policy; (b) permit allocations would likely assist and accelerate the directional change of the reform at the plant level and will therefore reduce uncertainty and allocative inefficiency; and (c) permit allocation will not result in dynamic inefficiency as a result of (a) and (b) unless coincident 'log-rolling, ${ }^{4}$ policies by the Government, to meet other objectives such as concerns over ongoing security of electricity supply, dictate otherwise. As Argy (1999, p. 73) has noted:

No economist can lay down firm rules on trade-offs involving efficiency, employment and equity. It is in the political arena that decisions to intervene ultimately have to be made. Economists can only help politicians make choices by assessing distributional effects and quantifying the efficiency benefits...

\section{Summary and conclusion}

The primary purpose of this article has been to review the efficacy of an all-auction approach to permit allocation under an ETS. A key finding was that the economic losses by incumbent coal generators would be material and a range of quantitative studies indicate losses ranging between $20 \%$ and $80 \%$. From a partial equilibrium perspective, there would appear to be no basis for which an all-auction approach might lead to a more efficient outcome than a partial allocation approach at the commencement of an ETS. Through partial allocation, transaction costs would be minimized, moral hazard would not be applicable, no new government funding would be required, and the intended objective of the policy would not be "corrupted" provided permits are fungible to the firm and thus would not represent a production subsidy. Had some form of ETS been on foot for the past 8 years, as has been the case in the EU via Phases I and II, then the above arguments simply would not hold. However, a big-bang approach would seem to be

\footnotetext{
4 'Log-rolling' essentially entails the implementation of complementary reforms as a form of ex ante social smoothing, that is, to soften the harsh impacts of a reform if its effects are likely to be unevenly distributed.
} 
especially problematic in the Australian case, with $82 \%$ of power coming from coal-fired capacity. And while so-called wind-fall gains may have occurred through permit allocation in the EU ETS, this does not make the policy incorrect, only its application.

Critically, this paper found that only 10 firms are now active in the generation capacity development space and approximately \$20 billion in new power station investment is required over the next 10 years. Survival of these firms is important, but exit or distraction of some firms would seem predictable under an all-auction approach to permit allocation. In the short run, this paper argued that electricity prices would rise excessively as firms are forced to act "strategically" by withholding capacity from the spot and forward electricity markets. In the intermediate run, system reliability would be compromised in line with declining levels of preventive maintenance capital on marginal coal power stations. And in the long run, capital losses incurred in the short and intermediate run would manifest themselves as a key risk and priced accordingly in forward investments in the sector. This would be a form of sovereign risk and would raise the cost and the task of new entry. This seems to be especially problematic for an investment-led policy.

On balance, the potential for a material misallocation of resources through an all-auction approach to Australian power generators would seem to be extremely high. Thus on dynamic efficiency grounds, there is a case for structural adjustment assistance; a once-and-for-all partial allocation of permits, and importantly, provided permits are fungible, the intention and objective would be to transition the pack, not their individual plants.

\section{References}

ACIL Tasman, (2007), "National Greenhouse Gas Emissions Trading Scheme - the case for compensation of disproportionate asset value loss”, ACIL Tasman publication, Canberra.

ACIL Tasman, (2008), “The impact of an ETS on the energy supply industry”, ACIL Tasman publication, Brisbane.

Argy, F. (1999), "Distribution effects of structural change: some policy implications", in Structural adjustment - exploring the policy issues, Productivity Commission, Canberra: AusInfo, pp 39-92.

CRA International, (2008), “NGF Greenhouse Gas Modelling”, CRAI Paper to the National Generator Forum.

Dixit, A. and Olson, M. (2000), “Does voluntary participation undermine the Coase Theorem?”, Journal of Public Economics, 76(2000): 309-335.

Ergas, H. (2008), “Auctions vs grandfathering”, A Concept Economics Briefing Paper, Concept Economics, Canberra.

esaa: Energy Supply Association of Australia, (2008), Electricity Gas Australia, esaa publication, Melbourne.

Frontier Economics, (2008), “Options for the design of emissions trading schemes in Australia”, Frontier Economics Publication, Melbourne. Available at www.garnautreview.org.au

Garnaut: Garnaut Climate Change Review, (2008), "Emissions trading scheme discussion paper", Melbourne. Available at www.garnautreview.org.au

Henney, A. and Neuhoff, K. (2008), “The experience of the European Union emissions trading scheme”, A Multiclient Study.

IMOWA: Independent Market Operator of Western Australia, (2007), Statement of Opportunities, IMOWA Publication, available at www.imowa.com.au 
Johnson, O. (1994), "Managing adjustment costs, political authority and implementation of adjustment programs with special reference to African countries”, World Development, 22:3(399-411).

Johnson, O. and Salop, J. (1980), "Distributional aspects of stabilisation programs in developing countries", IMF Staff Papers, Vol 27, March, pp. 1-23.

MMA: McLennan Magasanik and Associates, (2006), Impacts of a National Emissions Trading Scheme on Australia’s Electricity Markets, prepared for National Emissions Trading Taskforce (NETT)

NEMMCo: National Electricity Market Management Company, (2007) Statement of Opportunities, NEMMCo Publication, available at www.nemmco.com.au

NETTS, (2007), "Possible Design for a Greenhouse Gas Emissions Trading System, further definition of the auction proposals for the NETT Discussion Paper”, Prepared by Evans and Peck, August 2007. www.emissionstrading.nsw.gov.au.

Nsouli, S., Rached, M. and Funke, N. (2002), "The speed of adjustment and the sequencing of economic reforms: issues and guidelines for policy makers”, IMF Working Paper, WP/02/132, International Monetary Fund.

Pasour, E. (1973), "Economic growth and agriculture: an evaluation of the compensation principle", Amercian Journal of Agricultural Economics, 55(4):611-616.

Simshauser, P. (2005), "The gains from the microeconomic reform of the power generation industry in East-Coast Australia”, Economic Analysis \& Policy, 35(1-2): 23-43.

Simshauser and Doan, (2009), "On wealth transfers, emissions trading and the wounded bull scenario", Australian Economic review, 42(1): forthcoming.

Srinivasan, T. (1985), "Neoclassical political economy, the state and economic development”, Asian Development Review, 3:2(38-58).

TGET: Task Group on Emissions Trading, (2007), "Report of the Task Group on Emissions Trading”, Department of the Prime Minister and Cabinet, Canberra, available at http://pandora.nla.gov.au/pan/79623/20071127-1411/www.dpmc.gov.au/publications/emissions 